\title{
Random mating and absence of sexual selection for B chromosomes in two natural populations of the grasshopper Eyprepocnemis plorans
}

\author{
M. D. LÓPEZ-LEÓN, M. C. PARDO, J. CABRERO \& J. P. M. CAMACHO \\ Departamento de Genética, Facultad de Ciencias, Universidad de Granada, E-18071 Granada, Spain
}

\begin{abstract}
The effects of B chromosomes on mating behaviour in natural populations of the grasshopper Eyprepocnemis plorans were investigated by collecting mating pairs in the field. The results have shown random mating and the absence of sexual selection related to the presence of Bs. Possible hypotheses explaining the maintenance of this polymorphism, despite the absence of drive and sexual selection, are discussed.
\end{abstract}

Keywords: B chromosomes, heterotic, mating pattern, mating success, neutral, parasitic.

\section{Introduction}

B chromosomes constitute one of the most frequent polymorphisms in natural populations of many plant and animal species. Their biological role, however, is not yet clear. They are mostly considered as genomic parasites (Östergren, 1945) because they are frequently harmful for the individuals carrying them (Müntzing, 1963; Nur, 1966, 1969; Puertas et al., 1985) but maintain themselves at the expense of accumulation mechanisms (see Jones, 1985). Most B chromosome polymorphisms hitherto studied fit this pattern. However, there are at least two species where the maintenance of the $\mathrm{B}$ polymorphism may be based on more complex and until now unknown mechanisms: Allium schoenoprasum (Holmes \& Bougourd, 1989) and Eyprepocnemis plorans (López-León et al., 1992) in which the absence of any accumulation mechanism of $\mathrm{B}$ chromosomes open the possibility that they could be B chromosomes fitting the heterotic model suggested by White (1973), by which Bs could have some beneficial effect on individuals carrying them. Thus, it is necessary to investigate the possible effects of these B chromosome systems on various components of individual fitness.

Correspondence: Juan Pedro M. Camacho, Departamento de Genética, Facultad de Ciencias, Universidad de Granada, E-18071 Granada, Spain.
The present paper analyses the possible effects of B chromosomes on mating behaviour in natural populations of the grasshopper E. plorans. The prolonged copulation period usually carried out by mating pairs in this species (about $24 \mathrm{~h}, \mathrm{M}$. D. López-León et al., unpublished data) facilitated sampling of a high number of mating pairs in the field. The results showed random mating and absence of sexual selection in both sexes in relation to the presence of B chromosomes.

\section{Materials and methods}

Mating pairs of the grasshopper Eyprepocnemis plorans were collected in the field at Jete and Salobreña (Granada, Spain). The former population was sampled in 1986 and 1990, and the latter only in 1990. Males and females of each mating pair were stored in a vial, carried to the laboratory and fixed for cytological analysis. To test the possible existence of sexual selection, samples of non-mating males and females were simultaneously collected in each population.

Testes were fixed in 1:3 acetic ethanol without any pretreatment. Females, however, had to be injected with 0.05 per cent colchicine in insect saline solution for $6 \mathrm{~h}$ prior to fixation of ovarioles in 1:3 acetic ethanol. Squashes of testis follicles and ovarioles were C-banded by the technique described in Camacho et al. (1984). 


\section{Results}

The analysis of the results was made in terms of the three main components of mating behaviour: differential male mating success, differential female mating success and pattern of mating (Santos et al., 1986). Three samples were studied, J1986 (Jete in 1986), J1990 (Jete in 1990) and S1990 (Salobreña in 1990). Karyotypic classes with two or more B chromosomes were grouped in the class $2 \mathrm{~B}^{+}$for statistical analyses. Comparisons were made with the log-likelihood ratio test, or $G$ statistic (Sokal \& Rohlf, 1981).

\section{$J 1986$}

Table 1 shows the karyotype frequencies observed in both mating and non-mating individuals from Jete collected in 1986. Mating and non-mating males did not show significant differences in karyotype frequencies $\left(G_{2}=0.01, P=0.99\right)$, and the same result was obtained for mating and non-mating females $\left(G_{2}=3.67, P=0.16\right)$. Consequently, there was no differential male or female mating success related to the presence of the $\mathrm{B}$ chromosome. Table 2 shows the composition of the 71 mating pairs analysed. A $G$-test shows that mating occurs at random with respect to $\mathrm{B}$ chromosomes $\left(G_{4}=8.40, P=0.08\right)$.

\section{$J 1990$}

Table 3 shows the karyotype frequencies in mating and non-mating individuals collected at Jete in 1990. The results are consistent with those observed 4 years before because there is no differential male $\left(G_{2}=2.26\right.$, $P=0.32)$ or female $\left(G_{2}=0.07, P=0.97\right)$ mating success. Furthermore, the composition of the 72 mating pairs analysed shows that mating is at random in this population (Table 4$)\left(G_{4}=1.31, P=0.86\right.$ ).

\section{$S 1990$}

Karyological frequencies of mating and non-mating individuals are shown in Table 5. G-tests show the absence of differential male $\left(G_{2}=4.30, P=0.12\right)$ or

Table 1 Karyotypic frequencies of mating and non-mating males and females collected at Jete in 1986

\begin{tabular}{|c|c|c|c|c|c|c|c|c|c|}
\hline \multirow[b]{2}{*}{ Sex } & \multirow{2}{*}{$\begin{array}{l}\text { Type of } \\
\text { individuals }\end{array}$} & \multicolumn{7}{|c|}{ Number of B chromosomes } & \multirow[b]{2}{*}{$\bar{x}_{\mathrm{B}}$} \\
\hline & & OB & $1 \mathrm{~B}$ & $2 B$ & $3 B$ & $4 B$ & $5 B$ & Total & \\
\hline \multirow[t]{3}{*}{ Male } & Mating & 22 & 30 & 15 & 3 & 1 & - & 71 & 1.028 \\
\hline & Non-mating & 26 & 34 & 20 & 2 & - & - & 82 & 0.976 \\
\hline & Total & 48 & 64 & 35 & 5 & 1 & - & 153 & 1.000 \\
\hline \multirow[t]{3}{*}{ Female } & Mating & 19 & 36 & 13 & 2 & - & 1 & 71 & 1.028 \\
\hline & Non-mating & 22 & 49 & 9 & - & - & - & 80 & 0.838 \\
\hline & Total & 41 & 85 & 22 & 2 & - & 1 & 151 & 0.927 \\
\hline Total & & 89 & 149 & 57 & 7 & 1 & 1 & 304 & 0.964 \\
\hline
\end{tabular}

$\bar{x}_{\mathrm{B}}=$ mean number of $\mathrm{B}$ chromosomes.

Table 2 Frequency of mating pairs collected at Jete in 1986

\begin{tabular}{|c|c|c|c|c|c|c|c|}
\hline \multirow[b]{2}{*}{ Female } & \multicolumn{7}{|l|}{ Male } \\
\hline & $0 \mathrm{~B}$ & $1 \mathrm{~B}$ & $2 B$ & $3 B$ & 4B & Total & $\bar{x}_{\mathrm{B}}$ \\
\hline OB & 3 & 8 & 7 & 1 & - & 19 & 1.316 \\
\hline $1 \mathrm{~B}$ & 11 & 15 & 7 & 2 & 1 & 36 & 1.083 \\
\hline $2 B$ & 6 & 6 & 1 & - & - & 13 & 0.563 \\
\hline $3 B$ & 2 & - & - & - & - & 2 & 0 \\
\hline $5 B$ & - & 1 & - & - & - & 1 & 1 \\
\hline Total & 22 & 30 & 19 & 3 & 1 & 71 & 1.028 \\
\hline $\bar{x}_{\mathrm{B}}$ & 1.318 & 1.067 & 0.632 & 0.667 & 1.000 & 1.028 & \\
\hline
\end{tabular}

$\bar{x}_{\mathrm{B}}=$ mean number of $\mathrm{B}$ chromosomes. 
Table 3 Karyotypic frequencies of mating and non-mating males and females collected at Jete in 1990

\begin{tabular}{llrrrrrr}
\hline & & \multicolumn{6}{c}{ Number of B chromosomes } \\
\cline { 3 - 7 } Sex & $\begin{array}{l}\text { Type of } \\
\text { individuals }\end{array}$ & 0B & 1B & 2B & 3B & Total & $\bar{x}_{\mathrm{B}}$ \\
\hline Male & Mating & 22 & 31 & 18 & 1 & 72 & 0.972 \\
& Non-mating & 58 & 62 & 25 & 3 & 148 & 0.818 \\
& Total & 80 & 93 & 43 & 4 & 220 & 0.868 \\
Female & Mating & 32 & 26 & 14 & - & 72 & 0.750 \\
& Non-mating & 24 & 21 & 8 & 2 & 55 & 0.782 \\
& Total & 56 & 47 & 22 & 2 & 127 & 0.764 \\
\multirow{2}{*}{ Total } & & 136 & 140 & 65 & 6 & 347 & 0.830 \\
\hline
\end{tabular}

$\bar{x}_{\mathrm{B}}=$ mean number of $\mathrm{B}$ chromosomes.

Table 4 Frequency of mating pairs collected at Jete in 1990

\begin{tabular}{lcccccl}
\hline \multirow{5}{*}{ Female } & Male & & & & & \\
\cline { 2 - 7 } & & $1 \mathrm{~B}$ & 2B & 3B & Total & $\bar{x}_{\mathrm{B}}$ \\
\hline 0B & 9 & 16 & 6 & 1 & 32 & 0.969 \\
1B & 8 & 10 & 8 & - & 26 & 1.000 \\
2B & 5 & 5 & 4 & - & 14 & 0.929 \\
Total & 22 & 31 & 18 & 1 & 72 & 0.972 \\
$\bar{x}_{\mathrm{B}}$ & 0.818 & 0.645 & 0.889 & 0 & 0.750 & \\
\hline
\end{tabular}

$\bar{x}_{\mathrm{B}}=$ mean number of $\mathrm{B}$ chromosomes

Table 5 Karyotypic frequency of mating and non-mating males and females collected at Salobreña in 1990

\begin{tabular}{llllllll}
\hline & & \multicolumn{6}{c}{ Number of B chromosomes } \\
\cline { 3 - 7 } Sex & $\begin{array}{l}\text { Type of } \\
\text { individuals }\end{array}$ & 0B & 1B & 2B & 3B & Total & $\bar{x}_{\mathrm{B}}$ \\
\hline Males & Mating & 13 & 25 & 11 & 3 & 52 & 1.077 \\
& Non-mating & 58 & 66 & 21 & 4 & 149 & 0.805 \\
& Total & 71 & 91 & 32 & 7 & 201 & 0.876 \\
\multirow{4}{*}{ Female } & Mating & 17 & 25 & 10 & - & 52 & 0.865 \\
& Non-mating & 15 & 11 & 2 & 1 & 29 & 0.621 \\
& Total & 32 & 36 & 12 & 1 & 81 & 0.778 \\
\multirow{2}{*}{ Total } & & 103 & 127 & 44 & 8 & 282 & 0.846 \\
\hline
\end{tabular}

$\bar{x}_{\mathrm{B}}=$ mean number of $\mathrm{B}$ chromosomes.

female $\left(G_{2}=3.07, P=0.22\right)$ mating success with respect to the $\mathrm{B}$ chromosome. The frequencies of the different mating combinations (Table 6) are consistent with random mating $\left(G_{4}=4.48, P=0.34\right)$.
Table 6 Frequency of mating pairs collected at Salobreña in 1990

\begin{tabular}{|c|c|c|c|c|c|c|}
\hline \multirow[b]{2}{*}{ Female } & \multicolumn{6}{|l|}{ Male } \\
\hline & OB & 1B & $2 B$ & 3B & Total & $\bar{x}_{\mathrm{B}}$ \\
\hline $\mathrm{OB}$ & 3 & 10 & 3 & 1 & 17 & 1.118 \\
\hline 1B & 9 & 9 & 7 & 1 & 26 & 1.000 \\
\hline $2 B$ & 1 & 6 & 1 & 1 & 9 & 1.222 \\
\hline Total & 13 & 25 & 11 & 3 & 52 & 1.077 \\
\hline $\bar{x}_{\mathrm{B}}$ & 0.846 & 0.840 & 0.818 & 1.000 & 0.846 & \\
\hline
\end{tabular}

$\bar{x}_{\mathrm{B}}=$ mean number of $\mathrm{B}$ chromosomes.

\section{Discussion}

This is the first study of the effect of B chromosomes on mating behaviour performed in natural conditions. The results indicate random mating and an absence of sexual selection related to the presence of B chromosomes. In E. plorans there is paternity displacement based on a strong second male sperm precedence $(\mathrm{M}$. D. López-León et al., submitted) and the existence of sexual selection at the level of sperm competition cannot be ruled out because some karyotypes could be fitter than others in assuring paternity. This should be investigated.

The present results are consistent with the general idea of the dispensability of B chromosomes which could be the result of their heterochromatic nature. In fact, the only structural genes hitherto reported in B chromosomes are ribosomal RNA genes (see Jones \& Rees, 1982; Green, 1990; López-León et al., 1991), which are usually redundant with those of the normal genome. Unspecific transcriptional activity of B chromosomes has been detected in some cases (Green, 1988; Brockhouse et al., 1989), but not in others (Sieger et al., 1970; Fox et al., 1974; Ishak et al., 1991). The absence of effects of $\mathrm{B}$ chromosomes of $E$. plorans on mating behaviour could be a logical consequence of their genic inactivity. In fact, the $\mathrm{B}_{2}$ type (the most frequent variant in Jete and Salobreña populations) possess a nucleolus organizer region (NOR) which is usually inactive due to methylation (López-León et al., 1991). It is reasonable to think, therefore, that the effects of these B chromosomes are mainly derived from their physical presence rather than from genetic activity. Thus, it seems that the presence of B chromosomes in E. plorans has more influence at an endophenotypic level, i.e. on chiasma frequency (Camacho et al., 1980) and NOR activity (Cabrero et al., 1987), than at an exophenotypic level (Camacho et al., 1980); the present results reinforce this argument. 
Several hypotheses try to explain the maintenance of the widespread B chromosome polymorphism lacking drive existing in E. plorans (López-León et al., 1992). Two antogonic models have hitherto been proposed, the parasitic (Östergren, 1945) and the heterotic (White, 1973). A B chromosome system should be classified as heterotic or parasitic only after analysing all the fitness components in the most natural conditions possible, the transmission rate in controlled crosses and at populational level, as deduced from the study of gravid females and their offspring. The same B chromosome may be beneficial for a certain character but harmful for another. The absence of effects of B chromosomes on mating behaviour in E. plorans suggests that they may be neutral for this character. Given that they do not exhibit accumulation mechanisms and our current understanding of the mechanisms involved we can provisionally conclude that B chromosomes in this species are neither parasitic nor heterotic, they seem to be neutral.

\section{Acknowledgements}

This study was partially supported by grants from the Dirección General de Investigación Científica y Técnica (no. PB90-0865) and the Plan Andaluz de Investigación, Grupo no. 3122 (Spain).

\section{References}

BROCKHOUSE, C., BAS, J. A. B., FERADAY, R. M. AND STRAUSS, N. A. 1989. Supernumerary chromosomes evolution in the $\mathrm{Si}$ mulium vernum group (Diptera: Simuliidae). Genome, 32, 516-521.

CABRERO, J., ALCHE, J. D. AND CAMACHO, J. P. M. 1987. Effects of B chromosomes of the grasshopper Eyprepocnemis plorans on nucleolar organiser regions activity. Activation of a latent NOR on a B chromosome fused to an autosome. Genome, 29, 116-121.

CAMACHO, J. P. M., CARBAllo, A. R. AND CABRERO, J. 1980. The Bchromosome system of the grasshopper Eyprepocnemis plorans subsp. plorans (Charpentier). Chromosoma, 80, 163-176.

CAMACHO, J. P. M., VISERAS, E., NAVAS-CASTILLO, J. AND CABRERO, J. 1984. C-heterochromatin content of supernumerary chromosome segments of grasshoppers: detection of an euchromatic extra segment. Heredity, 53, 167-175.
FOX, D. P., HEWITT, G. M. AND HALL, D. J. 1974. DNA replication and RNA transcription of euchromatic and heterochromatic chromosome regions during grasshopper meiosis. Chromosoma, 45, 43-62.

GREEN, D. M. 1988. Cytogenetics of the endemic New Zealand frog, Leiopelma hochstetteri: extraordinary supernumerary chromosome variation and a unique sexchromosome system. Chromosoma, 97, 55-70.

GREEN, D. M. 1990. Muller's Ratchet and the evolution of supernumerary chromosomes. Genome, 33, 818-824.

HOLMES, D. S. AND BOUGOURD, S. M. 1989. B-chromosome selection in Allium schoenoprasum. I. Natural populations. Heredity, 63, 83-87.

ISHAK, B., JAAFAR, H., MAETZ, J. L. AND RUMPLER, Y. 1991. Absence of transcriptional activity of the B-chromosomes of Apodemus peninsulae during pachytene. Chromosoma, 100, 278-281.

JONES, R. N. 1985. Are B chromosomes 'selfish'? In: CavalierSmith T. (ed.) The Evolution of Genome Size, John Wiley and Sons Ltd, Chichester, pp. 397-425.

JONES, R. N. AND REES, H. 1982. B chromosomes. Academic Press, London.

López-León, M. D., CABRero, J. AND CAMACho, J. P. M. 1991. A nucleolus organizer region in a $\mathrm{B}$ chromosome inactivated by DNA methylation. Chromosoma, 100, 134-138.

LOPEZ-LEON, M. D., CABRERO, J., CAMACHO, J. P. M., CANO, M. I. AND SANTOS, J. L. 1992. A widespread B chromosome polymorphism maintained without apparent drive. Evolution, 46, 529-539.

MUNTZING, A. 1963. Effects of accessory chromosomes in diploid and tetraploid rye. Hereditas, 49, 361-426.

NUR, U. 1966. Harmful supernumerary chromosomes in a mealy bug population. Genetics, 54, 1225-1238.

NUR, U. 1969. Harmful B-chromosomes in a mealy bug; additional evidence. Chromosoma, 28, 280-297.

OSTERGReN, G. 1945. Parasitic nature of extra fragment chromosomes. Bot. Notiser, 2, 157-163.

PUERTAS, M. J., ROMERA, F. AND DE LA PEÑA, A. 1985. Comparison of B chromosome effects on Secale cereale and Secale vaviloii. Heredity, 55, 229-234.

SANTOS, M., TARRIO, R., ZAPATA, C. AND ALVAREZ, G. 1986. Sexual selection on chromosomal polymorphism in Drosophila subobscura. Heredity, 57, 161-169.

SIEGER, M., PERA. F. AND SCHWARZACHER, H. G. 1970. Genetic inactivity of heterochromatin and heteropycnosis in Microtus agrestis. Chromosoma, 29, 349-364.

SOKAL, R. R. AND ROHLF, F. J. 1981. Biometry (2nd edn). W. H. Freeman, San Francisco.

WHITE, M. J. D. 1973. Animal Cytology and Evolution (3rd edn). Cambridge University Press, London. 